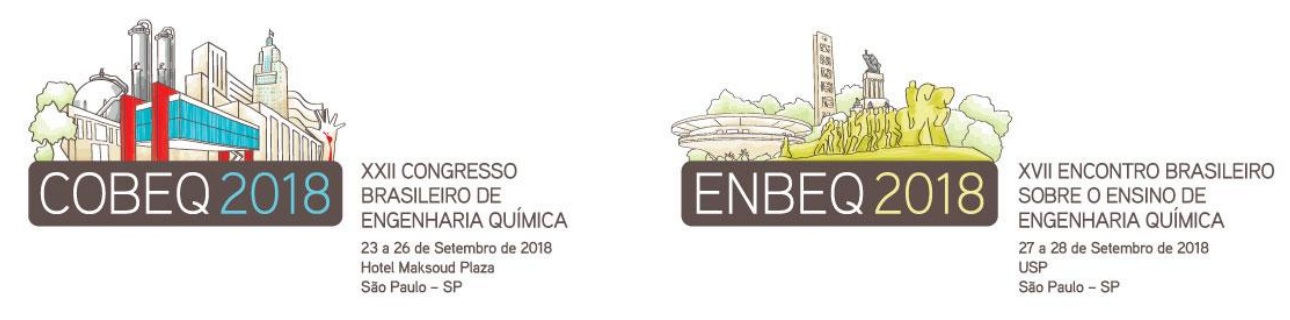

\title{
UTILIZAÇÃO DE ULTRASSOM NA PRODUÇÃO DE PASTA DE AZEITONA
}

\author{
TEIXEIRA HRD ${ }^{1,2}$, FELTRIN VP $^{1}$, STEINMACHER NC $^{1}$, PERES AMCL $^{2}$ e BARALDI IJ ${ }^{1}$ \\ ${ }^{1}$ Universidade Tecnológica Federal do Paraná - Campus Medianeira, Departamento \\ Acadêmico de Alimentos \\ ${ }^{2}$ Instituto Politécnico de Bragança - Bragança - Portugal \\ E-mail para contato: baraldi@utfpr.edu.br
}

\begin{abstract}
RESUMO - Produziu-se pasta de azeitonas pelo método tradicional, e para preservar o produto aplicou-se pasteurização à $100{ }^{\circ} \mathrm{C}$, e alternativamente ao tratamento térmico aplicou-se ultrassom à $25{ }^{\circ} \mathrm{C}$ com tempo e potência determinados por um planejamento fatorial completo. Sendo efetuados análises microbiológicas e análises de textura (dureza, adesividade, elasticidade e coesividade). Verificou-se que o ultrassom foi mais eficiente que a pasteurização na redução de bactérias mesófilas, e também possui efeitos sobre a dureza da pasta $(p<0,05)$ em função do tempo e potências aplicadas.
\end{abstract}

\section{INTRODUÇÃO}

Os produtos derivados da azeitona como o azeite e as azeitonas fermentadas, fizeram desde sempre, parte da dieta mediterrânea. Contudo com o passar do tempo vem ganhando o mundo (Boskou, 2006). A necessidade do aproveitamento das azeitonas que não possuam aparência desejada, mas que sejam igualmente próprias para o consumo humano levou ao desenvolvimento da pasta de azeitona, que segundo o COI (2015) é o produto obtido do corte muito fino das azeitonas de mesa sem caroços.

As tecnologias de processamentos de alimentos são dinâmicas e em constante evolução, em busca de atender os anseios dos consumidores e atingir os padrões de qualidade exigidos dos produtos. O ultrassom (US) surge como uma destas novas tecnologias, considerada limpa e que pode ser aplicada em alimentos (Alves et al., 2013). Estudos utilizando ultrassom demonstram que sua aplicação é eficiente em processos de homogeneização, elimina microrganismos, inativa enzimas e aumenta eficiência nos processos de extração (Mason et al., 1996). Logo se espera que esta tecnologia substitua o processo de pasteurização e homogeneização, simplificando o processo de produção da pasta de azeitona e ao mesmo tempo mantendo ou melhorando os parâmetros de qualidade.

\section{MATERIAIS E MÉTODOS}

As pastas de azeitona foram produzidas seguindo a receita de Rodrigues (2012), $88 \mathrm{~g}$ de azeitonas de mesa curadas e trituradas, $9 \mathrm{~g}$ de azeite, $3 \mathrm{~g}$ de suco de limão e 0,2 gramas de 

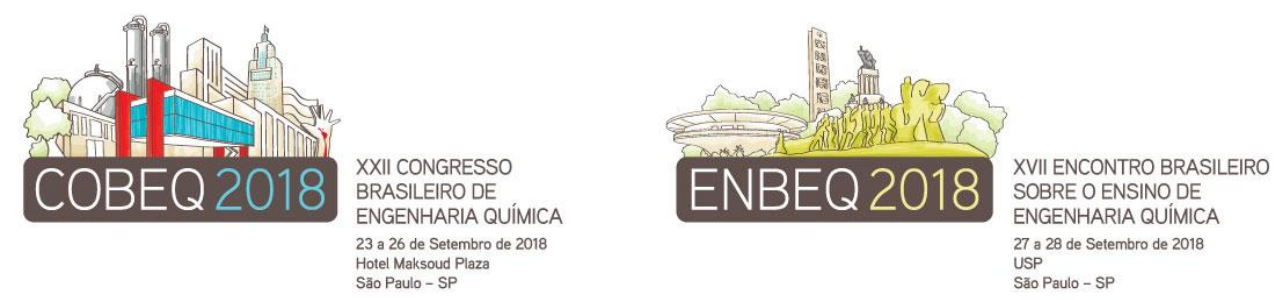

orégano, seguido de homogeneização mecânica dos ingredientes, produzindo um pasta com $\mathrm{pH}<4,0, \operatorname{logo}$ após foi coletada a amostra controle, e em seguida as pastas foram acondicionadas em os frascos de vidro, utilizados na produção de conservas com tampa metálica (diâmetro $4,0 \mathrm{~cm}$ e altura $4,0 \mathrm{~cm}$ ), contendo 40 gramas de produto, que foi fechado e submetido a aquecimento em água em ebulição $\left(100{ }^{\circ} \mathrm{C}\right)$ por 10 minutos (pasta de azeitona pasteurizada), ambos os processos foram executados em triplicata, para análises microbiológicas e de textura. Alternativamente substitui-se a homogeneização mecânica e pasteurização por tratamento em banho de ultrassom (Elmasonic P $120 \mathrm{H}-800 \mathrm{~W}$, Elma Alemanha) na temperatura de $25{ }^{\circ} \mathrm{C}$ e com frequência de $37 \mathrm{kHz}$, e as condições de tempo variando de 10 a 40 minutos e potência variando de 40 a 100\%, e os ensaios foram elaborados de seguindo um planejamento fatorial completo (PFC) com três repetições no ponto central (PC) (Box; Woodall, 2012).

As variáveis dependentes do PFC foram às análises microbiológicas (Bactérias Mesófilas e Bolores e leveduras), executadas seguindo a norma ISO 4833:2003 e as recomendações da APHA (American Public Health Association) conforme descrito por Silva et al. (2010), e as análises de textura foram executadas conforme metodologia definida como análise do perfil de textura (TPA) (Rosenthal, 2010), que compreende os valores de dureza, adesividade, elasticidade e coesividade foram realizadas em texturômetro TA.HD.Plus (Godalming, UK), aplicando ao probe de teste uma velocidade de pré-teste $5,0 \mathrm{~mm} / \mathrm{s}$, velocidade de teste $5,0 \mathrm{~mm} / \mathrm{s}$, velocidade de pós-teste $10,0 \mathrm{~mm} / \mathrm{s}$, distância de amostre de 15,0 $\mathrm{mm}$, com penetração na amostra de $40,0 \mathrm{~mm}$ e a força aplicada é exercia por uma massa de $5,0 \mathrm{~g}$.

Para análise estatística aplicou-se ANOVA (análise de variância) para determinar os efeitos das variáveis independentes (tempo e potência) nos parâmetros de textura $(\mathrm{p}<0,05)$. Para comparar as análises da amostra controle e tratamento térmico utilizou-se o método de Tukey com p<0,05 (Box; Woodall, 2012).

\section{RESULTADOS E DISCUSSÕES}

Os resultados do PFC encontram-se na Tabela 1, e aplicando ANOVA verifica-se que somente para a variável dependente dureza ( $\mathrm{g}$ ) as variáveis independentes possuem efeitos significativos $(p<0,05)$, podendo a dureza ser representada pela Equação 1, com $R^{2}=0,9992$. Concluindo-se que podemos controlar a dureza da pasta de azeitona ajustando a potência e tempo de sonificação. Para os outros parâmetros de textura (adesividade, elasticidade e coesividade) não existe diferenças significativas entre o controle e a pasteurizada $(p<0,05)$ (Tabela 2), e são semelhantes aos resultados obtidos no PFC (Tabela 1).

Dureza $(\mathrm{g})=-36,0040+6,21111 . \mathrm{t}+6.8611 . \mathrm{P}-0,1861 . \mathrm{P} . \mathrm{t}$

Onde: $\mathrm{t}$ - tempo em minutos e $\mathrm{P}$ - potência em porcentagem

Observa-se também na Tabela 1 que as bactérias mesófilas apresentaram resultados < $10^{2} \mathrm{UFC} / \mathrm{g}$ para todos os ensaios, enquanto que os resultados são estatisticamente iguais para a pasta controle e a pasta pasteurizada (Tabela 2), com valores na ordem de $10^{3}$ a $10^{2} \mathrm{UFC} / \mathrm{g}$ respectivamente, indicando o US foi mais eficiente na redução de bactérias mesófilas. 


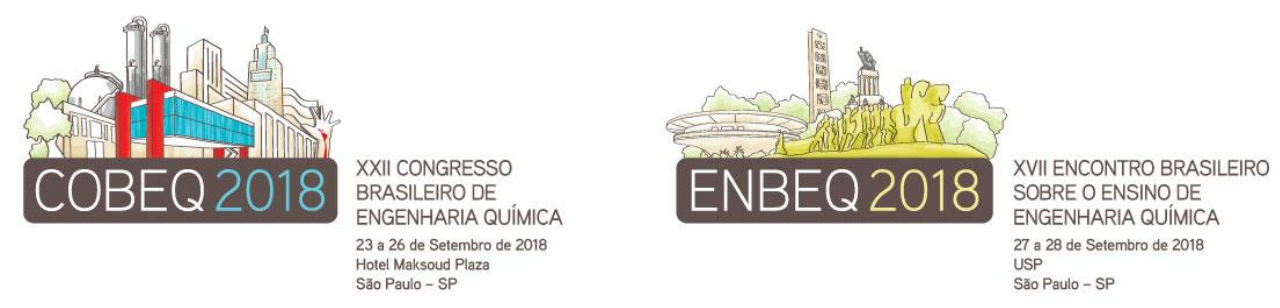

Quando se compara as análises de bolores e leveduras, observa-se uma redução de um escala logarítmica quando se aplica o ultrassom, os resultados ficam na ordem de $10^{3}$ (Tabela 1), enquanto as amostras controle estão na ordem de $10^{4}$ e as pasteurizadas na ordem de $10^{3}$ (Tabela 2), porém são estatisticamente iguais $(\mathrm{p}<0,05)$. Verifica-se então um limitada ação do US nos Bolores e Leveduras na condições testadas.

Tabela 1 - Resultados do PFC do tratamento ultrassônico a $25{ }^{0} \mathrm{C}$

\begin{tabular}{ccccccccc}
\hline Ensaio & $\begin{array}{c}\text { tempo } \\
(\text { min. })\end{array}$ & $\begin{array}{c}\text { potência } \\
(\%)\end{array}$ & $\begin{array}{c}\text { dureza } \\
(\mathrm{g})\end{array}$ & $\begin{array}{c}\text { adesividade } \\
(\mathrm{g} . \mathrm{s})\end{array}$ & $\begin{array}{c}\text { elasticidade } \\
(\%)\end{array}$ & $\begin{array}{c}\text { coesivi- } \\
\text { dade }(\%)\end{array}$ & $\begin{array}{c}\text { mesófilas } \\
(\mathrm{UFC} / \mathrm{g})\end{array}$ & $\begin{array}{l}\text { B\&L } \\
(\mathrm{UFC} / \mathrm{g})\end{array}$ \\
\hline 1 & 10 & 40 & 226 & -73 & 0,997 & 0,57 & $<10^{2}$ & $7,0 \cdot 10^{3}$ \\
2 & 40 & 40 & 189 & -71 & 0,997 & 0,64 & $<10^{2}$ & $9,0 \cdot 10^{3}$ \\
3 & 10 & 100 & 526 & -92 & 1,098 & 0,71 & $<10^{2}$ & $8,7 \cdot 10^{3}$ \\
4 & 40 & 100 & 154 & -82 & 0,997 & 0,61 & $<10^{2}$ & $8,5 \cdot 10^{3}$ \\
$5(\mathrm{PC})$ & 25 & 70 & 278 & $-89,3$ & 0,997 & 0,59 & $<10^{2}$ & $1,7 \cdot 10^{3}$ \\
$6(\mathrm{PC})$ & 25 & 70 & 267 & $-88,6$ & 0,997 & 0,60 & $<10^{2}$ & $1,9 \cdot 10^{3}$ \\
7 (PC) & 25 & 70 & 277 & $-88,1$ & 0,995 & 0,67 & $<10^{2}$ & $2,0 \cdot 10^{3}$ \\
\hline
\end{tabular}

${ }^{*} \mathrm{~B} \& \mathrm{~L}=$ Bolores e Leveduras

Tabela 2 - Comparação das amostras controle com a pasteurizada.

\begin{tabular}{lcc}
\hline \multicolumn{1}{c}{ Análises } & Controle & pasteurizada \\
\hline Bactérias mesófilas (UFC/g) & $(3,3 \pm 1,2) \cdot 10^{3 \mathrm{a}}$ & $(4,7 \pm 1,2) \cdot 10^{2} \mathrm{a}$ \\
Bolores e Leveduras (UFC/g) & $(6,6 \pm 1,2) \cdot 10^{4} \mathrm{a}$ & $(4,9 \pm 1,0) \cdot 10^{3 \mathrm{a}}$ \\
Dureza (g) & $218 \pm 6^{\mathrm{a}}$ & $256 \pm 14^{\mathrm{a}}$ \\
Adesividade (g.s) & $-68 \pm 5^{\mathrm{a}}$ & $-71 \pm 2^{\mathrm{a}}$ \\
Elasticidade (\%) & $0,9987 \pm 0,0012^{\mathrm{a}}$ & $0,9973 \pm 0,0003^{\mathrm{a}}$ \\
Coesividade (\%) & $0,49 \pm 0,03^{\mathrm{a}}$ & $0,51 \pm 0,02^{\mathrm{a}}$ \\
\hline
\end{tabular}

$\mathrm{n}=3, \mathrm{M} \pm \mathrm{EP}$, teste de Tukey nas linhas com $\mathrm{p}<0,05$. 


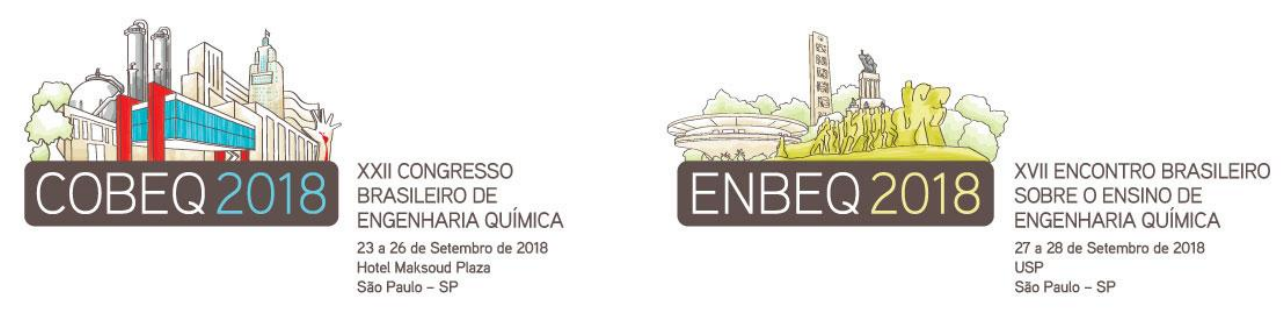

\section{CONCLUSÕES}

A tecnologia do Ultrassom quando aplicada na produção de pastas de azeitonas $\left(25{ }^{0} \mathrm{C}\right)$, mesmo aplicado em um tempo igual ao aquecimento em água a $100{ }^{0} \mathrm{C}$ é mais eficiente na redução de Bactérias Mesófilas, porém não é mais eficiente na redução de bolores e leveduras. E o tempo de sonificação e potência podem ser utilizados para ajustar a dureza da pasta de azeitona na faixa de trabalho testada.

\section{REFERÊNCIAS}

ALVES, A.D.L. CICHOSKI, A.J. BARIN, J.S. RAMPELOTTO, S.B. DURANTE, E.C. O ultrassom no amaciamento de carnes. Ciência Rural, Santa Maria, v.43, n.8, p.1522-1528, ago, 2013.

BOSKOU, D. Characteristics of the Olive Tree and Olive Fruit. Olive oil chemistry and technology, second edition, p. 2-4, 2006.

BOX, G. E. P. WOODALL, W.H. Innovation, Quality Engineering, and Statistics. Quality Engineering. V.24, pp. 20-29, 2012.

COI (INTERNATIONAL OLIVE OIL COUNCIL). Preliminary draft guide for extra virgin olive oil quality competitions. Agosto, 2015.

ISO 4833: INTERNACIONAL ORGANIZATION FOR STANDARDIZATION. Microbiology of food and animal feeding stuffs - Horizontal method for the enumeration of microorganisms - Colony-count technique at $30{ }^{\circ} \mathbf{C}$., $n^{\circ} 4833,2003$.

MASON, T. PANIWNYK, L. LORIMER. J. P. L. The uses of ultrasound in food technology. Ultrasonics Sonochemistry v. 3, pp. S253-S260. 1996.

RODRIGUES, Nuno. Preparação de Pastas com Azeitona de Mesa Transmontana. 2012, 84 f. Dissertação (mestrado em Qualidade e Segurança Alimentar) - Escola Superior Agrária de Bragança. Bragança, 2012.

ROSENTHAL, A.J. texture profile analysis- how important are the parameters. Journal of Texture Studies V. 41 pp. 672-684, 2010.

SILVA, N. JUNQUEIRA, V.C.A. SILVERIA, N.F.A TANIWAKI, M.H. SANTOS, R.F.S. GOMES, R.A.R. Manual de métodos de Análise microbiológica de Alimentos e Água. 4 ed. p.33-99. LIVRARIA VARELA. 2010. 